\title{
Genetic diversity of Blastocystis in kindergarten children in southern Xinjiang, China
}

Meng Qi ${ }^{1,2}$, Zilin Wei ${ }^{2}$, Ying Zhang ${ }^{2}$, Qiyuan Zhang ${ }^{2}$, Juanfeng $\mathrm{Li}^{1}$, Longxian Zhang ${ }^{1 *}$ and Rongjun Wang ${ }^{1 *}$

\begin{abstract}
Background: Blastocystis is one of the most common intestinal parasites in humans and various animals worldwide. Few studies are available regarding the genetic characterization of Blastocystis infections in humans in China.

Methods: In the present study, 609 fecal samples were collected from two- to six-year-old kindergarten children in southern Xinjiang and were examined by polymerase chain reaction (PCR).

Results: The infection rate of Blastocystis was 14.3\% (87/609); no significant difference was observed among counties and between sexes. Blastocystis subtypes ST1 $(n=38)$, ST2 $(n=8)$, and ST3 $(n=41)$ were identified by sequence analysis of the small subunit ribosomal RNA gene. Genetic polymorphisms were observed at the intra-subtype level, including seven variations for ST1 (ST1A to ST1G), four for ST2 (ST2A to ST2D), and two for ST3 (ST3A and ST3B); with ST1F and ST2B being new variations.
\end{abstract}

Conclusions: ST1 and ST3 are the two common Blastocystis subtypes in the study area. More extensive studies in both humans and animals in different regions are needed to better characterize the transmission of Blastocystis.

Keywords: Blastocystis, SSU rRNA, genetic polymorphism, children, Xinjiang

\section{Background}

Blastocystis transmitted by the fecal-oral route, is a strictly unicellular protozoan that inhabits the gastrointestinal tract in humans and animals [1]. Although the pathogenicity of Blastocystis remains controversial, its infection is associated with various gastrointestinal disorders, irritable bowel syndrome, and cutaneous lesions $[2,3]$. Moreover, patients infected with Blastocystis have been observed to be relieved of clinical signs after successful treatment [4-6]. It is estimated that over one billion individuals have been infected with Blastocystis throughout the world [7]. Nevertheless, the infection rates of Blastocystis vary widely among regions, possibly

\footnotetext{
*Correspondence: zhanglx8999@henau.edu.cn; wrj-1978@henau.edu.cn ${ }^{1}$ College of Animal Science and Veterinary Medicine, Henan Agricultural University, Zhengzhou 450002, Henan, People's Republic of China Full list of author information is available at the end of the article
}

reaching $30 \%$ and $30-76 \%$ in industrialized and developing nations, respectively [8-11].

There is extensive genetic variation within the genus Blastocystis. Based on molecular analyses of the smallsubunit ribosomal RNA (SSU rRNA), 17 subtypes (ST1 to ST17) have been described, ST1 to ST9 are identified in both humans and animals, while the others are exclusively identified in animals $[12,13]$. ST3 is the most commonly detected subtype in humans, followed by ST1, ST2 and ST4, whereas ST5 to ST9 are rarely found $[14,15]$. In addition, genetic diversity varies dramatically among Blastocystis subtypes as well as at the intra-subtype level [16-18].

In China, the first report of Blastocystis infection in humans was published in 1990 [19]. Since then, a high prevalence and abundant genetic diversity of Blastocystis have been found in humans, non-human primates, and domestic and wild animals [20,21]. So far, six different

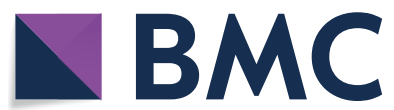

(c) The Author(s) 2020. This article is licensed under a Creative Commons Attribution 4.0 International License, which permits use, sharing, adaptation, distribution and reproduction in any medium or format, as long as you give appropriate credit to the original author(s) and the source, provide a link to the Creative Commons licence, and indicate if changes were made. The images or other third party material in this article are included in the article's Creative Commons licence, unless indicated otherwise in a credit line to the material. If material is not included in the article's Creative Commons licence and your intended use is not permitted by statutory regulation or exceeds the permitted use, you will need to obtain permission directly from the copyright holder. To view a copy of this licence, visit http://creativecommons.org/licenses/by/4.0/. The Creative Commons Public Domain Dedication waiver (http://creativecommons.org/publicdomain/zero/1.0/) applies to the data made available in this article, unless otherwise stated in a credit line to the data. 
subtypes (ST1 to ST6) have been identified in humans from 12 provinces, with ST3 being the most dominant subtype [20]. In contrast, Blastocystis infection has been identified in animals in eight provinces: 10 known (ST1 to ST7, ST10, ST13 and ST14), and four novel (Novel 1, Novel 2, Novel 3 and Novel 4) subtypes have been reported [20]. Nevertheless, no report is available regarding Blastocystis infection in both humans and other animals in Xinjiang Uygur Autonomous Region (hereafter referred to as Xinjiang), China. The aim of the present study was to estimate the prevalence and genetic diversity of Blastocystis in kindergarten children in Xinjiang, China.

\section{Methods}

\section{Sample collection}

From August 2017 to January 2019, 609 fresh fecal samples were collected from kindergarten children (two to six years of age) located in Tumushuke, Payzawat, Shufu, Yopurga, Yecheng, Hotan, Baicheng, Poskam, Kuqa, Pishan, and Lop of southern Xinjiang, China (Fig. 1). After being informed of the study purpose and procedures in writing by kindergarten staff, parents or guardians who agreed to their children's participation were given a plastic fecal collector labeled with a unique number. Fresh stool samples were collected in the morning. No diarrhea was observed during sampling. In total, 609 fecal samples were collected, transported to the laboratory and stored at $4{ }^{\circ} \mathrm{C}$ prior to further analysis.

\section{DNA extraction and PCR amplification}

Genomic DNA was extracted from the fecal samples using the E.Z.N.A ${ }^{\circledR}$ Stool DNA Kit (Omega Bio-tek, Inc., Norcross, GA, USA), according to manufacturer-recommended procedures. Blastocystis subtypes were determined by PCR amplification of an approximately $600 \mathrm{bp}$ fragment of the $S S U$ rRNA gene using the primers RD5 (5'-ATC TGG TTG ATC CTG CCA GT-3') and BhRDr (5'-GAG CTT TTTA ACT GCA ACA ACG-3'); the PCR reaction conditions were adopted from a previous report [22]. Positive controls (a positive sample already successfully sequenced) were included in each amplification reaction. The PCR products were visualized by electrophoresis in $1 \%$ agarose gels (w/v) with GelRed ${ }^{\mathrm{TM}}$ (Biotium Inc., Hayward, CA, USA) staining.

\section{Sequencing and phylogenetic analyses}

Positive PCR products were sequenced by Genewiz (Suzhou, China); accuracy was confirmed by two-directional sequencing. Nucleotide sequences were aligned with reference sequences from the GenBank database using the program ClustalX 2.01 (http://www.clust

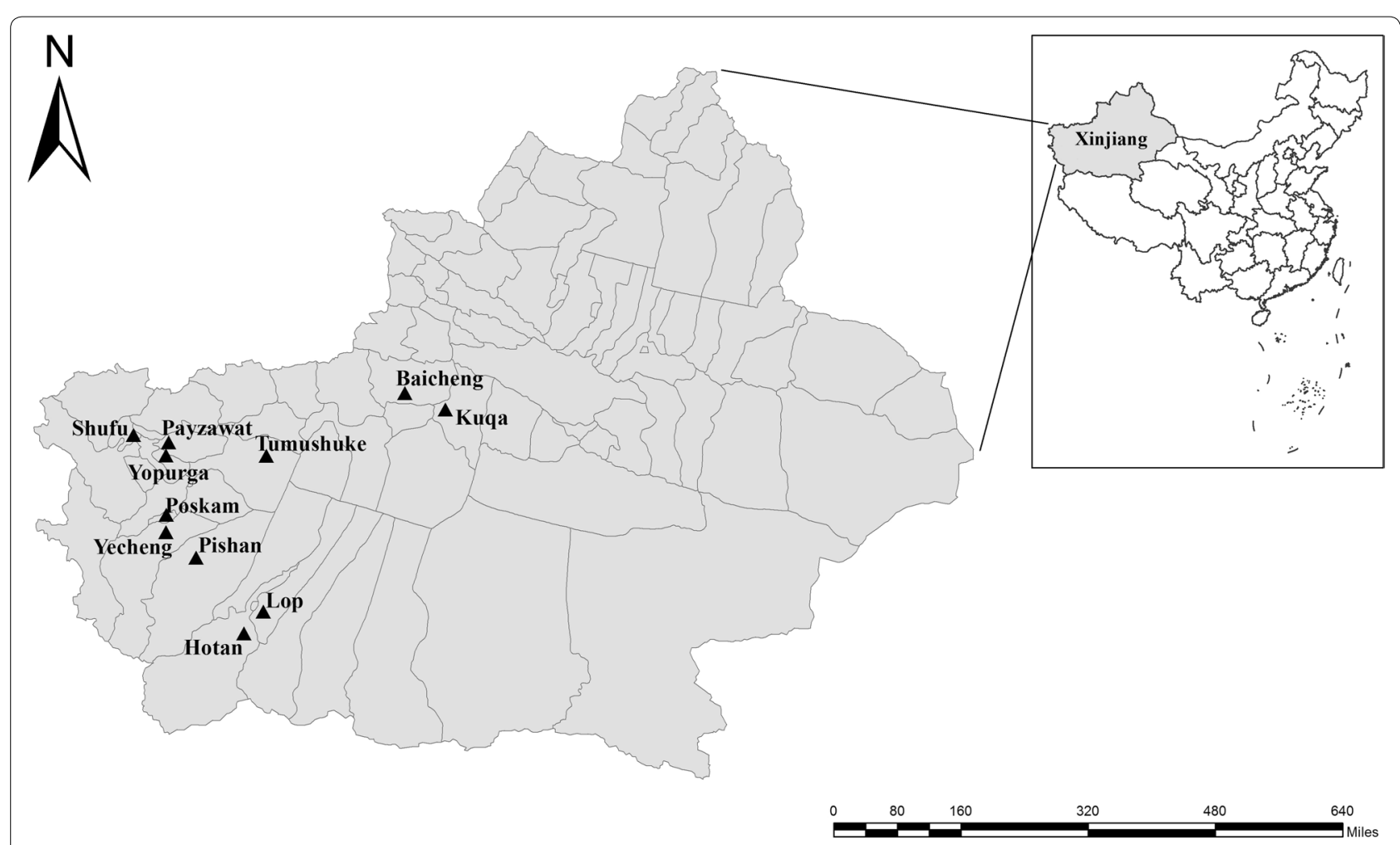

Fig. 1 Geographical location of the study. Triangles indicate the sampling locations in southern Xinjiang, China 
al.org/) to determine the subtypes. Phylogenetic analysis adopted a neighbor-joining model of the aligned sequences implemented in MEGA7 (http://www.megas oftware.net/), with 1000 replicates to assess the robustness of clusters.

\section{Statistical analysis}

The Chi-square test was used to compare Blastocystis prevalences. Differences were considered significant when $P<0.05$.

\section{Results}

\section{Prevalence of Blastocystis}

The PCR analysis of 609 fecal samples showed the presence of Blastocystis oocysts in 87 samples (14.3\%) from 11 counties investigated (Table 1$)$. The highest $(23.8 \%$, $15 / 63)$ and lowest $(5.7 \%, 2 / 35)$ prevalences were observed in Yopurga and Poskam, respectively $\left(\chi^{2}=5.14, d f=1\right.$, $P<0.05)$ (Table 1). There was no significant difference in the prevalence of Blastocystis between males (14.7\%) and females (13.9\%) $\left(\chi^{2}=0.09, d f=1, P>0.05\right)$ (Table 1).

\section{Distribution of Blastocystis subtypes}

The DNA sequence analyses of the SSU rRNA gene products revealed the presence of three Blastocystis subtypes, ST1 (38/87), ST2 (8/87) and ST3 (41/87) (Table 1). Subtype ST3 was dominant in most of the counties surveyed, with ST1 appearing to be the predominant subtype in the Lop county and only ST1 being identified in the Poskam county (Table 1). The predominance of subtype ST3 was found both in males and females, followed by subtypes ST1 and ST2 (Table 1).

\section{The polymorphic nature of the SSU rRNA gene of Blastocystis}

Seven variations of the ST1 subtype were identified by sequence alignment analysis, with the similarity ranging between $99.0-99.7 \%$. ST1A, comprising 19 out of 40 ST1 subtypes, was the dominant sequence type, followed by the variations $\operatorname{ST} 1 \mathrm{~B}(n=13)$ and $\operatorname{ST} 1 \mathrm{C}(n=4)$. The variations ST1D, ST1E, ST1F and ST1G were detected in only one sample each (Table 1). Likewise, nine ST2 isolates produced four variations (ST2A to ST2D), with a similarity of 99.5-99.8\%. In contrast, little difference was observed in the ST3 subtype. Forty-three ST3 isolates formed two variations (ST3A and ST3B) and only one nucleotide difference was noticed between them. Among these types, ST1F and ST2B represented new variations. Phylogenetic analysis also confirmed the polymorphic nature of the SSU rRNA gene of Blastocystis isolates in this study (Fig. 2).

\section{Discussion}

Blastocystis infection was shown to be prevalent in kindergarten children in the study area; the overall infection rate of $14.3 \%$ was identical to the $14.3 \%(1 / 7)$ prevalence reported in children $<5$ years of age in Yunnan Province [23]. Nevertheless, the rate is significantly lower than that in some developing countries, such as Nigeria (83.9\%, 167/199; 2-14 years of age) and Turkey (38.0\%, $115 / 303 ; 3-13$ years of age) [24, 25]. In China, the average infection rate of Blastocystis in humans was $3.4 \%$ $(3625 / 107,695)$ [20], with the highest prevalence being 43.3\% (215/497) in Guangxi Province [26]; the lowest rate was $0.80 \%(85 / 10,652)$ in Fujian Province [27]. Previous studies have suggested that the variation in the prevalence of human Blastocystis infection may be closely related to the immune status and age of the hosts and different geographical locations [23, 27-30]. In addition, infection with Blastocystis was associated with drinking unboiled water in a hill village in Yunnan Province, China [23]. An outbreak of human Blastocystis infection was observed following ingestion of contaminated running water, and over 1122 patients with diarrhea were identified [31]. There was no significant difference in Blastocystis prevalence associated with sex in this study, which was similar to the findings of previous studies $[23,28]$.

In this study, subtypes ST1 $(n=38), \operatorname{ST} 2(n=8)$ and ST3 $(n=41)$ were identified by using sequence analysis of the $S S U$ rRNA gene, with the predominance of subtype ST3 being found both in males and females, followed by subtypes ST1 and ST2. This distribution of Blastocystis subtypes is similar to that found in most countries of the world $[14,15]$. In contrast, the most dominant subtype in Spain and Denmark was reported to be ST4 [18, 32]. It is reported that the prevalence of Blastocystis is affected by various epidemiological and demographic factors such as climate, geography, cultural habits, and exposure to reservoir hosts [15].

In China, six Blastocystis subtypes (ST1 to ST6) have been identified and most of the samples represented single-subtype infections, while mixed infections were also observed (such as ST1+ST2, ST1 + ST3, ST2 + ST3, ST3+ST5), and some subtypes were novel [23, 29, 30, 33]. Among them, ST3 $(62 \%, 186 / 300)$ is the dominant subtype and has been identified in almost all reports from China [23, 29, 30, 33]. In addition, ST3 is also a commonly identified subtype in humans in Europe, Africa, Oceania and the Middle East [14, 34-36].

As observed in the present study, genetic diversity varies dramatically among Blastocystis subtypes, as well as at the intra-subtype level. However, whether genetic diversity is associated with symptoms or not is far from clear. Dogruman et al. [37] reported that ST2 was associated with asymptomatic infection. In another study by 
Table 1 The infection rate and subtype distribution of Blastocystis in kindergarten children at different locations in Xinjiang, China

\begin{tabular}{|c|c|c|c|}
\hline Collection site & Sex & $\begin{array}{l}\text { No. positive/total no. } \\
\text { examined (\%) }\end{array}$ & Subtype \\
\hline \multirow[t]{3}{*}{ Tumushuke } & Male & $4 / 33(12.1)$ & $\operatorname{ST1C}(n=1) ; \operatorname{ST3A}(n=2) ; \operatorname{ST} 3 B(n=1)$ \\
\hline & Female & $1 / 29(3.5)$ & $\operatorname{ST} 3 \mathrm{~A}(n=1)$ \\
\hline & Subtotal & $5 / 62(8.1)$ & $\operatorname{ST1C}(n=1) ; \operatorname{ST3A}(n=3) ; \operatorname{ST3B}(n=1)$ \\
\hline \multirow[t]{3}{*}{ Payzawat } & Male & $0 / 14(0)$ & \\
\hline & Female & $1 / 11(9.1)$ & $\operatorname{ST} 3 \mathrm{~A}(n=1)$ \\
\hline & Subtotal & $1 / 25(4.0)$ & $\operatorname{ST} 3 \mathrm{~A}(n=1)$ \\
\hline \multirow[t]{3}{*}{ Shufu } & Male & $3 / 26(11.5)$ & $\operatorname{ST1B}(n=1) ; \operatorname{ST3A}(n=1) ; \operatorname{ST} 3 \mathrm{~B}(n=1)$ \\
\hline & Female & $6 / 22(27.3)$ & $\operatorname{ST1D}(n=1) ; \operatorname{ST3A}(n=3) ; \operatorname{ST3B}(n=2)$ \\
\hline & Subtotal & $9 / 48(18.8)$ & $\operatorname{ST1B}(n=1) ; \operatorname{ST1D}(n=1) ; \operatorname{ST3A}(n=4) ; \operatorname{ST3B}(n=3)$ \\
\hline \multirow[t]{3}{*}{ Yopurga } & Male & $6 / 34(17.7)$ & $\operatorname{ST1A}(n=1) ; \operatorname{ST1B}(n=1) ; \operatorname{ST} 2 \mathrm{~A}(n=1) ; \operatorname{ST} 3 \mathrm{~A}(n=3)$ \\
\hline & Female & $9 / 29(31.0)$ & $\operatorname{ST1B}(n=1) ; \operatorname{ST1E}(n=1) ; \operatorname{ST2A}(n=2) ; \operatorname{ST} 2 \mathrm{~B}(n=1) ; \operatorname{ST3A}(n=3) ; \operatorname{ST} 3 \mathrm{~B}(n=1)$ \\
\hline & Subtotal & $15 / 63(23.8)$ & $\operatorname{ST1A}(n=1) ; \operatorname{ST1B}(n=2) ; \operatorname{ST1E}(n=1) ; \operatorname{ST2A}(n=3) ; \operatorname{ST2B}(n=1) ; \operatorname{ST3A}(n=6) ; \operatorname{ST} 3 \mathrm{~B}(n=1)$ \\
\hline \multirow[t]{3}{*}{ Yecheng } & Male & $7 / 46(15.2)$ & $\operatorname{ST1A}(n=5) ; \operatorname{ST3A}(n=2)$ \\
\hline & Female & 9/43 (20.9) & $\operatorname{ST1A}(n=6) ; \operatorname{ST3A}(n=3)$ \\
\hline & Subtotal & $16 / 89(18.0)$ & $\operatorname{ST1A}(n=11) ; \operatorname{ST} 3 \mathrm{~A}(n=5)$ \\
\hline \multirow{3}{*}{ Hotan } & Male & $8 / 40(20.0)$ & $\operatorname{ST1A}(n=3) ; \operatorname{ST1B}(n=2) ; \operatorname{ST1C}(n=1) ; \operatorname{ST} 3 \mathrm{~B}(n=2)$ \\
\hline & Female & $3 / 40(7.5)$ & ST1B (1); ST3A (1); ST3B (1) \\
\hline & Subtotal & $11 / 80(13.8)$ & $\operatorname{ST1A}(n=3) ; \operatorname{ST} 1 \mathrm{~B}(n=3) ; \operatorname{ST1C}(n=1) ; \mathrm{ST} 3 \mathrm{~A}(n=1) ; \mathrm{ST} 3 \mathrm{~B}(n=3)$ \\
\hline \multirow[t]{3}{*}{ Baicheng } & Male & 2/11 (18.2) & $\operatorname{ST} 3 \mathrm{~A}(n=1) ; \mathrm{ST} 3 \mathrm{~B}(n=1)$ \\
\hline & Female & $1 / 12(8.3)$ & $\operatorname{ST} 3 \mathrm{~A}(n=1)$ \\
\hline & Subtotal & $3 / 23(13.0)$ & $\operatorname{ST3A}(n=2) ; \operatorname{ST3B}(n=1)$ \\
\hline \multirow[t]{3}{*}{ Poskam } & Male & $1 / 17(5.9)$ & $\operatorname{ST} 1 \mathrm{C}(n=1)$ \\
\hline & Female & $1 / 18(5.6)$ & $\operatorname{ST1A}(n=1)$ \\
\hline & Subtotal & $2 / 35(5.7)$ & $\operatorname{ST1A}(n=1) ; \operatorname{ST1C}(n=1)$ \\
\hline \multirow[t]{3}{*}{ Kuqa } & Male & $3 / 19(15.8)$ & $\operatorname{ST3A}(n=1) ; \operatorname{ST3B}(n=2)$ \\
\hline & Female & $1 / 19(5.3)$ & $\operatorname{ST} 3 \mathrm{~A}(n=1)$ \\
\hline & Subtotal & $4 / 38(10.5)$ & $\operatorname{ST} 3 \mathrm{~A}(n=2) ; \mathrm{ST} 3 \mathrm{~B}(n=2)$ \\
\hline \multirow[t]{3}{*}{ Pishan } & Male & $5 / 16(31.3)$ & $\operatorname{ST1C}(n=1) ; \operatorname{ST} 2 \mathrm{C}(n=2) ; \operatorname{ST} 3 \mathrm{~A}(n=2)$ \\
\hline & Female & $2 / 21(9.5)$ & $\operatorname{ST} 2 \mathrm{C}(n=1) ; \operatorname{ST} 3 \mathrm{~A}(n=1)$ \\
\hline & Subtotal & $7 / 37(18.9)$ & $\operatorname{ST1C}(n=1) ; \operatorname{ST2C}(n=3) ; \operatorname{ST} 3 \mathrm{~A}(n=3)$ \\
\hline \multirow[t]{3}{*}{ Lop } & Male & $5 / 43(11.6)$ & $\operatorname{ST1A}(n=1) ; \operatorname{ST1B}(n=2) ; \operatorname{ST} 3 \mathrm{~A}(n=1) ; \operatorname{ST} 3 \mathrm{~B}(n=1)$ \\
\hline & Female & 9/66 (13.6) & $\operatorname{ST1A}(n=1) ; \operatorname{ST} 1 \mathrm{~B}(n=5) ; \operatorname{ST} 1 \mathrm{~F}(n=1) ; \operatorname{ST} 2 \mathrm{D}(n=1) ; \operatorname{ST} 3 \mathrm{~A}(n=1)$ \\
\hline & Subtotal & $14 / 109(12.8)$ & $\operatorname{ST1A}(n=2) ; \operatorname{ST1B}(n=7) ; \operatorname{ST1F}(n=1) ; \operatorname{ST2D}(n=1) ; \operatorname{ST3A}(n=2) ; \operatorname{ST3B}(n=1)$ \\
\hline \multirow[t]{3}{*}{ Total } & Male & $44 / 299(14.7)$ & $\operatorname{ST1A}(n=10) ; \operatorname{ST1B}(n=6) ; \operatorname{ST1C}(n=4) ; \operatorname{ST2A}(n=1) ; \operatorname{ST2C}(n=2) ; \operatorname{ST3A}(n=13) ; \operatorname{ST} 3 \mathrm{~B}(n=8)$ \\
\hline & Female & $43 / 310(13.9)$ & $\begin{array}{l}\operatorname{ST1A}(n=8) ; \operatorname{ST1B}(n=7) ; \operatorname{ST1D}(n=1) ; \operatorname{ST} 1 \mathrm{E}(n=1) ; \operatorname{ST} 1 \mathrm{~F}(n=1) ; \operatorname{ST} 2 \mathrm{~A}(n=2) ; \mathrm{ST} 2 \mathrm{~B}(n=1) ; \\
\operatorname{ST2C}(n=1) ; \operatorname{ST} 2 \mathrm{D}(n=1) ; \mathrm{ST} 3 \mathrm{~A}(n=16) ; \mathrm{ST} 3 \mathrm{~B}(n=4)\end{array}$ \\
\hline & & $87 / 609(14.3)$ & $\begin{array}{l}\operatorname{ST1A}(n=18) ; \operatorname{ST1B}(n=13) ; \operatorname{ST1C}(n=4) ; \operatorname{ST1D}(n=1) ; \operatorname{ST1E}(n=1) ; \operatorname{ST1F}(n=1) ; \operatorname{ST2A}(n=3) ; \\
\operatorname{ST2B}(n=1) ; \operatorname{ST2C}(n=3) ; \operatorname{ST2D}(n=1) ; \operatorname{ST} 3 \mathrm{~A}(n=29) ; \operatorname{ST3B}(n=12)\end{array}$ \\
\hline
\end{tabular}

Note: $P>0.05$ for the difference in prevalence of Blastocystis between males and females

the same authors, ST3 was found to be the most common subtype in both symptomatic and asymptomatic groups, but there was no association between Blastocystis subtypes and gastrointestinal symptoms [38]. Similarly, three studies conducted in Thailand and Turkey suggested that ST3 was the most frequent subtype but did not observe a significant relationship between this subtype and gastrointestinal symptoms $[25,39,40]$.

\section{Conclusions}

A Blastocystis infection rate of $14.3 \%$ was identified in kindergarten children in southern Xinjiang, China, with no significant difference in Blastocystis prevalence between males and females. Three Blastocystis subtypes (ST1 to ST3) were identified by PCR and ST3 was the predominant subtype; in addition, genetic polymorphism was observed within subtypes. More extensive studies in 


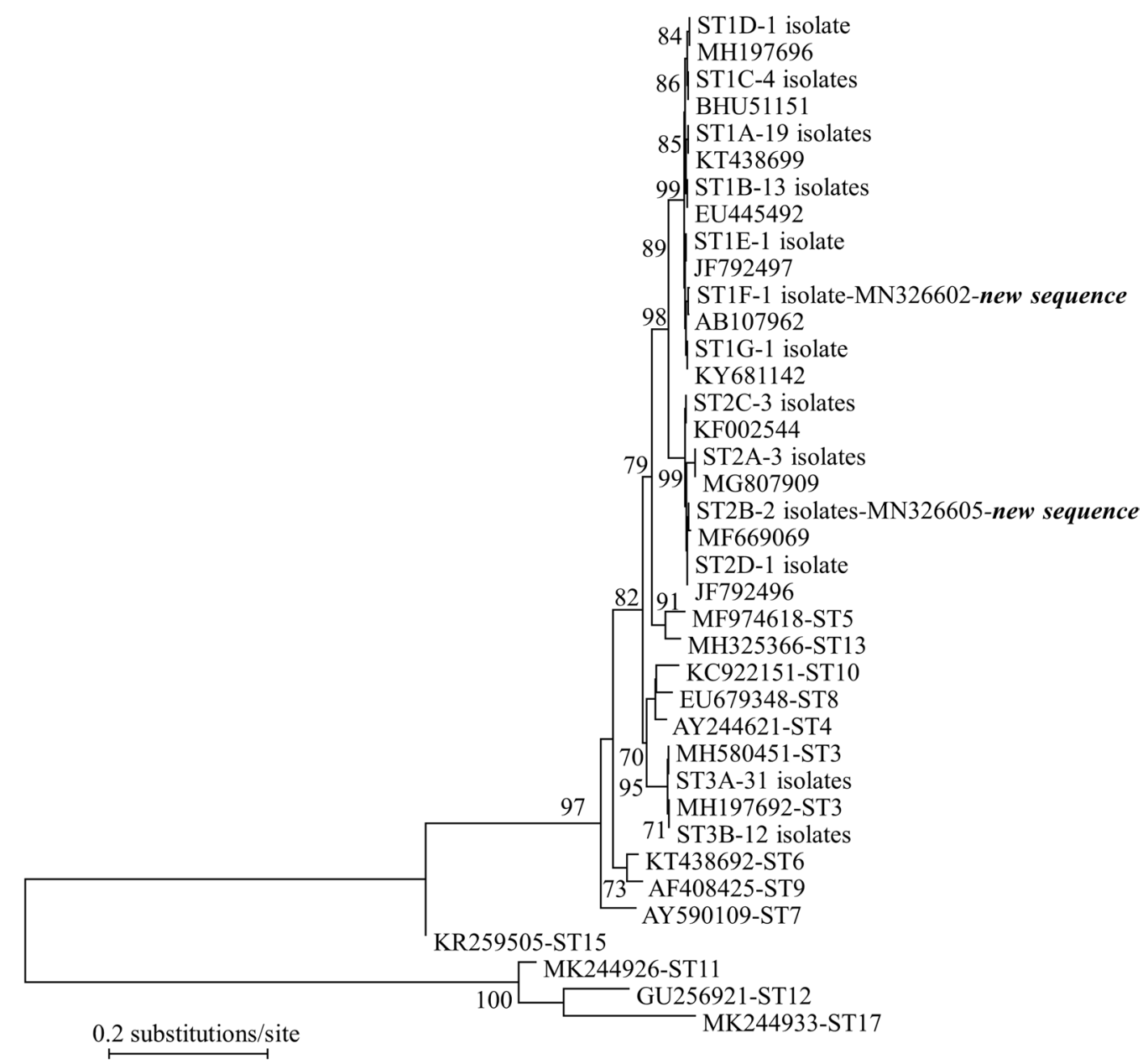

Fig. 2 Phylogenetic relationships among representative sequences of the Blastocystis small subunit ribosomal RNA (SSU rRNA) genes obtained from China, using the neighbor-joining method. Bootstrap values greater than 70\% from 1000 pseudo replicates are shown

both humans and animals in different areas are needed to better characterize the transmission of Blastocystis.

\section{Abbreviations}

PCR: polymerase chain reaction; SSU rRNA: small subunit ribosomal RNA; ST: sequence type.

\section{Acknowledgements}

We thank kindergarten staff for collecting samples.

\section{Authors' contributions}

LZ, MQ and RW conceived and designed the study. ZW, YZ and QZ collected the samples. MQ, ZW, $Y Z$ and $Q Z$ performed the experiments. $M Q, Z W, Y Z, Q Z$ and RW analyzed the data. RW and MQ wrote the manuscript. All authors read and approved the final manuscript.

\section{Funding}

This work was supported in part by the National Natural Science Foundation of China (31702227, 31672548), the National Key Research and Development Program of China (2017YFD0500405, 2017YFD0501305), and the Programme for Young and Middle-Aged Leading Science, Technology, and Innovation of Xinjiang Production \& Construction Group (2018CB034). The sponsors played no role in study design, in the collection, analysis, or interpretation of the data, in writing the report, or in the decision to submit the article for publication.

\section{Availability of data and materials}

Representative nucleotide sequences generated in this study were deposited in the GenBank database under the Accession Numbers MN326597-MN326609.

\section{Ethics approval and consent to participate}

The present study was performed according to the "Ethical Review of Biomedical Research Involving Humans" published by the National Health Commission, China. In addition, this research involving human participants was approved by the Ethics Review Committee of Henan Agricultural University (Approval No. IRC-HENAU-20160224-05). Parents or quardians of children have been informed of the study purpose and procedures in writing, and those consenting their children's participation have signed the forms of informed consent.

\section{Consent for publication}

Not applicable.

\section{Competing interests}

The authors declare that they have no competing interests. 


\section{Author details}

${ }^{1}$ College of Animal Science and Veterinary Medicine, Henan Agricultural University, Zhengzhou 450002, Henan, People's Republic of China. ${ }^{2}$ College of Animal Science, Tarim University, Alar 843300, Xinjiang, People's Republic of China.

Received: 18 September 2019 Accepted: 4 January 2020 Published online: 10 January 2020

\section{References}

1. Yoshikawa H, Tokoro M, Nagamoto T, Arayama S, Asih PB, Rozi IE, Syafruddin D. Molecular survey of Blastocystis sp. from humans and associated animals in an Indonesian community with poor hygiene. Parasitol Int. 2016;65:780-4.

2. Wawrzyniak I, Poirier P, Viscogliosi E, Dionigia M, Texier C, Delbac F, Alaoui HE. Blastocystis, an unrecognized parasite: an overview of pathogenesis and diagnosis. Ther Adv Infect Dis. 2013;1:167-78.

3. Cakir F, Cicek M, Yildirim IH. Determination the subtypes of Blastocystis sp. and evaluate the effect of these subtypes on pathogenicity. Acta Parasitol. 2019;64:7-12

4. Idris NS, Dwipoerwantoro PG, Kurniawan A, Said M. Intestinal parasitic infection of immunocompromised children with diarrhoea: clinical profile and therapeutic response. J Infect Dev Ctries. 2010;4:309-17.

5. Vogelberg C, Stensvold CR, Monecke S, Ditzen A, Stopsack K, Heinrich-Gräfe U, Pöhlmann C. Blastocystis sp. subtype 2 detection during recurrence of gastrointestinal and urticarial symptoms. Parasitol Int. 2010;59:469-71.

6. Dinleyici EC, Eren M, Dogan N, Reyhanioglu S, Yargic ZA, Vandenplas Y. Clinical efficacy of Saccharomyces boulardii or metronidazole in symptomatic children with Blastocystis hominis infection. Parasitol Res. 2011;108:541-5.

7. Scanlan PD, Stensvold CR. Blastocystis: getting to grips with our guileful guest. Trends Parasitol. 2013;29:523-9.

8. Tan KS. New insights on classification, identification, and clinical relevance of Blastocystis spp. Clin Microbiol Rev. 2008;21:639-65.

9. Souppart L, Sanciu G, Cian A, Wawrzyniak I, Delbac F, Capron M, Dei-Cas E, Boorom K, Delhaes L, Viscogliosi E. Molecular epidemiology of human Blastocystis isolates in France. Parasitol Res. 2009;105:413-21.

10. Scanlan PD, Stensvold CR, Rajilić-Stojanović M, Heilig HG, Vos WMD, O'Toole PW, Cotter PD. The microbial eukaryote Blastocystis is a prevalent and diverse member of the healthy human gut microbiota. FEMS Microbiol Ecol. 2015;90:326-30

11. Pandey PK, Verma P, Marathe N, Shetty S, Bavdekar A, Patole MS, Stensvold CR, Shouche YS. Prevalence and subtype analysis of Blastocystis in healthy Indian individuals. Infect Genet Evol. 2015;31:296-9.

12. Stensvold CR, Arendrup MC, Jespersgaard C, Mølbak K, Nielsen HV. Detecting Blastocystis using parasitologic and DNA-based methods: a comparative study. Diagn Microbiol Infect Dis. 2007:59:303-7.

13. Mónica S, María Teresa GMO, Gloria SA, Ronald F. Development of a new PCR protocol to detect and subtype Blastocystis spp. from humans and animals. Parasitol Res. 2011;109:205-12.

14. Stensvold CR, Alfellani ML, Prip K, Victory E, Maddox C, Nielsen H, Clark C. Subtype distribution of Blastocystis isolates from synanthropic and zoo animals and identification of a new subtype. Int J Parasitol Parasites Wildl. 2009:39:473-9.

15. Alfellani MA, Taner-Mulla D, Jacob AS, Imeede CA, Yoshikawa H, Stensvold CR, Clark CG. Genetic diversity of Blastocystis in livestock and zoo animals. Protist. 2013;164:497-509.

16. Rivera WL. Phylogenetic analysis of Blastocystis isolates from animal and human hosts in the Philippines. Vet Parasitol. 2008;156:178-82.

17. Parkar U, Traub RJ, Vitali S, Elliot A, Levecke B, Robertson I, Geurden T, Steele J, Drake B, Thompson RCA. Molecular characterization of Blastocystis isolates from zoo animals and their animal-keepers. Vet Parasitol. 2010;169:8-17.

18. Stensvolda CR, Clark CG. Levels of genetic diversity vary dramatically between Blastocystis subtypes. Infect Genet Evol. 2012;12:263-73.

19. He J, Jing J, Zhou H. Studies of light microscope appearance and ultrastructure of Blastocystis hominis in vitro culture. Acta Sci Natur Univ Sunyaatseni. 1990:29:122-8.

20. Deng L, Chai Y, Zhou Z, Liu H, Zhong Z, Hu Y, et al. Epidemiology of Blastocystis sp. infection in China: a systematic review. Parasite. 2019;26:41.

21. Xiao X, Zhou SH, Jiang N, Tian DZ, Zhou ZM, Zhang M, et al. First record of Leptospira and Blastocystis infections in captive flying squirrels (Trogopterus xanthipes) from Enshi County, China. Acta Trop. 2019;197:105065.
22. Ramírez JD, Sánchez LV, Bautista DC, Corredor AF, Flórez AC, Stensvold CR. Blastocystis subtypes detected in humans and animals from Colombia. Infect Genet Evol. 2014;22:223-8.

23. Li LH, Zhou XZ, Wang XZ, Wang LB, Jiang JY, Yoshikawa H, et al. Molecular epidemiology of human Blastocystis in a village in Yunnan province, China. Parasitol Int. 2007;56:281-6.

24. Poulsen CS, Efunshile AM, Nelson JA, Stensvold CR. Epidemiological aspects of Blastocystis colonization in children in Ilero, Nigeria. Am J Trop Med Hyg. 2016:95:175-9.

25. Dogan N, Aydin M, Tuzemen NU, Dinleyici EC, Oguz I, Dogruman-Al F. Subtype distribution of Blastocystis spp. isolated from children in Eskisehir, Turkey. Parasitol Int. 2017;66:948-51.

26. He SS, Wu LY, Liu XQ, Shi HH, Chen Z, Zhang H, et al. Investigation on the infection of Blastocystis hominis in populations in Bama Yao Autonomous County of Guangxi. Chin J Parasitol Parasit Dis. 2013;31:76-7.

27. Chen BJ, Xie HG, Zhan RY, Yan-Rong LI, Lin CX, Xie XL, Jian DW, Zhang SY. Human intestinal protozoa diseases in Fujian Province, China. Chin J Zoonoses. 2018;34:6.

28. Wang KX, Li CP, Wang J, Cui YB. Epidemiological survey of Blastocystis hominis in Huainan City, Anhui Province, China. World J Gastroenterol. 2002;8:928-32.

29. Li LH, Zhang XP, Lv S, Zhang L, Yoshikawa H, Wu Z, Steinmann P, Utzinger J, Tong XM, Chen SH. Cross-sectional surveys and subtype classification of human Blastocystis isolates from four epidemiological settings in China. Parasitol Res. 2007;102:83-90.

30. Zhang W, Ren G, Zhao W, Yang Z, Shen Y, Sun Y, Liu A, Cao J. Genotyping of Enterocytozoon bieneusi and subtyping of Blastocystis in cancer patients: relationship to diarrhea and assessment of zoonotic transmission. Front Microbiol. 2017;8:1835.

31. Wu G, Xiong Y, Cao G, Guang LI, Liu M, Zhu J. Investigation of an epidimic outbreak of blastocystisasis. Chin J Parasit Dis Control. 2000;13:25-7.

32. Domínguez-Márquez MV, Guna R, Muñoz C, Gómez-Muñoz MT, Borrás R. High prevalence of subtype 4 among isolates of Blastocystis hominis from symptomatic patients of health district of Valencia (Spain). Parasitol Res. 2009;105:949-55.

33. Yan Y, Su S, Ye J, Lai X, Lai R, Liao H, Chen G, Zhang R, Hou Z, Luo X. Blastocystis sp. subtype 5: a possibly zoonotic genotype. Parasitol Res. 2007;101:1527-32.

34. Silberman JD, Sogin ML, Leipe DD, Clark CG. Human parasite finds taxonomic home. Nature. 1996:380:398.

35. Forsell J, Granlund M, Stensvold CR, Clark CG, Evengård B. Subtype analysis of Blastocystis isolates in Swedish patients. Eur J Clin Microbiol Infect Dis. 2012;31:1697.

36. Moosavi A, Haghighi A, Mojarad EN, Zayeri F, Alebouyeh M, Khazan H, Kazemi B, Zali MR. Genetic variability of Blastocystis sp. isolated from symptomatic and asymptomatic individuals in Iran. Parasitol Res. 2012;111:2311-5.

37. Funda DA, Hande D, Hisao Y, Ozgur K, Mete D. A possible link between subtype 2 and asymptomatic infections of Blastocystis hominis. Parasitol Res. 2008;103:685-9.

38. Dogruman-Al F, Yoshikawa H, Kustimur S, Balaban N. PCR-based subtyping of Blastocystis isolates from symptomatic and asymptomatic individuals in a major hospital in Ankara, Turkey. Parasitol Res. 2009;106:263-8.

39. Ozyurt M, Kurt O, Molbak K, Vedel NH, Haznedaroglu T, Rune SC. Molecular epidemiology of Blastocystis infections in Turkey. Parasitol Int. 2008;57:300-6.

40. Jantermtor S, Pinlaor P, Pinlaor S, Sangka A, Wilailuckana C, Wongsena W, Yoshikawa H. Subtype identification of Blastocystis spp. isolated from patients in a major hospital in northeastern Thailand. Parasitol Res. 2013:112:1781-6.

\section{Publisher's Note}

Springer Nature remains neutral with regard to jurisdictional claims in published maps and institutional affiliations. 